\title{
Diversification of Follicular Cells in the Ovaries of the Horse Fly Haematopota italica (Diptera: Tabanidae). Similarities and Differences with the Drosophila Model System*
}

\author{
Mariusz K. JAGLARZ, Anna JABŁOŃSKA, Elżbieta KISIEL, and Szczepan M. BILIŃSKI
}

Accepted September 15, 2008

\begin{abstract}
JAGLARZ M. K., JABŁoŃSKA A., KISIEL E., BILIŃSKI S. M. 2009. Diversification of follicular cells in the ovaries of the horse fly Haematopota italica (Diptera: Tabanidae). Similarities and differences with the Drosophila model system. Folia biol. (Kraków) 57: $1-12$.

In insect ovaries, germ line cells are surrounded by somatic cells that initially form a uniform follicular epithelium. The subsequent diversification of the follicular cells into severa subpopulations enables specification of distinct structures in different regions of complex eggshells. It also influences the patterning of the future embryo. These processes have been extensively studied at both the cellular and molecular levels using the Drosophila ovary as a model system. It is not clear however, to what extent the Drosophila model of the follicular epithelium patterning is universal for the entire Diptera group. Here, we analyze the diversification of the follicular cells in a distant Drosophila relative, the horse fly, Haematopota italica. We found that in this species, there are 6 recognizably different follicular cell subpopulations within the previtellogenic ovarian follicles. Ultrastructural analysis of the follicular epithelium revealed two morphologically distinct clusters of follicular cells residing at the anterior and posterior poles of the follicles. Each cluster consists of 2-3 polar cells located centrally and surrounded by several outer cells called border cells (at the anterior pole) or border-like cells (at the posterior pole). During previtellogenesis, the clusters lose the initial symmetry as their cells differentiate and develop conspicuous cytoplasmic projections comprising cytoskeletal elements. Ultimately, the follicular cells of the anterior and posterior clusters become morphologically different and, as we suggest, participate in different processes during oogenesis and formation of the eggshell in H. italica.
\end{abstract}

Key words: Polar cells, insect ovary, oogenesis, Diptera.

Mariusz K. JAGLARZ, Anna JABEOŃSKA, Elżbieta KISIEL, Szczepan M. BILIŃSKI, Department of Systematic Zoology, Institute of Zoology, Jagiellonian University, R. Ingardena 6, PL 30-060 Kraków, Poland.

E-mail:jagla@zuk.iz.uj.edu.pl

The ovaries of higher dipterans (Diptera, Brachycera) show a general similarity in their structural composition. In all so far studied brachycerous flies, the paired ovaries consist of elongated elements, called ovarioles, that are of the meroisticpolytrophic type (for classification of insect ovarioles see BÜNING 1994; BILIŃSKI 1998). Within each ovariole, four usually well-defined regions can be distinguished along its anterior-posterior axis: the terminal filament, germarium, vitellarium and ovariolar pedicel (for further details see BÜNING 1994). The major part of the ovariole, the vitellarium, houses ovarian follicles or egg chambers which are linearly arranged and sequentially more advanced in oogenesis. The neighboring follicles are linked by interfollicular stalks and distributed spatially in such a way that younger (previtellogenic) follicles lie closer to the germarium, whereas those more developed (vitellogenic and choriogenic follicles) occupy the posterior region of the ovariole. In all brachycerous flies studied thus far, the overall morphological organization of the ovarian follicles is remarkably similar: 16 germline cells (a single oocyte and 15 polyploid nurse cells) are enveloped by a layer of somatic, mesodermal follicular cells (FCs), which form a follicular epithelium (reviewed in JAGLARZ et al. 2008). During oogenesis, the initially uniform FCs

\footnotetext{
*Supported by grants from the Ministry of Science and Higher Education: BW/IZ/17/2005 to M. K. JAGLARZ and DS/BiNoZ/IZ/780.
} 
diversify into several distinct subpopulations that are responsible for the formation of a regionally complex eggshell (for a review see DOBENS \& RAFTERY 2000; HORNE-BADOVINAC \& BILDER 2005; WU et al. 2008). In addition, certain FC subpopulations are engaged in the polarization of the oocyte and influence the patterning of the developing embryo (GONZALEZ-REYES et al. 1995; RAY \& SCHÜPBACH 1996; MOUSSIAN \& ROTH 2005).

Our current understanding of the sequence of cellular and molecular events leading to the formation of functional eggs in dipterans and other insects is based almost exclusively on studies of the model organism, the fruit fly, Drosophila melanogaster. In the wildtype ovaries of this species, new ovarian follicles after formation in the posteriormost zone of the germarium translocate into the vitellarium. Concurrently, the first signs of FC diversification become apparent within the follicular epithelium: two pairs of FCs situated at the opposite (i.e. anterior and posterior) poles of the follicle stop dividing and become rounded. These cells, termed the polar cells (PCs), are critical for subsequent patterning of the cuboidal FCs, which constitute the rest of the follicular epithelium (GONZALEZ-REYES \& ST JOHNSTON 1998; GRAMMONT \& IRVINE 2001, 2002; DENEF \& SCHÜPBACH 2003). Subsequently, after several cycles of mitotic divisions, the cuboidal FCs differentiate into two distinct subpopulations: (1) terminal cells, surrounding the anterior and posterior PCs, and (2) the mainbody FCs covering the lateral aspect of the follicle. It has been demonstrated that the terminal regions are originally symmetrically prepatterned into distinct domains whose further fates depend on the distance from the PCs (GONZALEZ-REYES \& ST JOHNSTON 1998; GRAMMONT \& IRVINE 2001, 2002; DENEF \& SCHÜPBACH 2003). The TGF $\alpha$ protein encoded by gurken plays a key role in breaking the symmetry of the terminal regions. This signaling molecule is secreted from the oocyte posterior pole and induces terminal cells flanking the posterior PCs to acquire the posterior fate (GONZALEZ-REYES et al. 1995; RAY \& SCHÜPBACH 1996; ROTH 2001; DENEF \& SCHÜPBACH 2003). In the anterior pole of the follicle, Gurken signaling is absent and as a result the anterior terminal cells differentiate into three subdomains. In the currently accepted model (GRAMMONT \& IRVINE 2002; XI et al. 2003), these subdomains are specified by the Unpaired ligand, a signaling molecule secreted by the anterior PCs. During mid-previtellogenesis, all mainbody FCs migrate posteriorly and form a columnar epithelium over the oocyte. At the same time, the three anterior terminal domains differentiate into morphologically distinct subpopulations: border, stretched and centripetal FCs. Subsequently, the border cells delaminate from the epithelium, tightly surround the anterior PCs, and together these cells push their way through the nurse cell compartment as they migrate toward the oocyte (NIEWIADOMSKA et al. 1999; MONTELL 2003, 2006). Concurrently, the stretched cells expand and form a thin, squamous epithelium that covers the nurse cells, while the centripetal cells begin migrating in between the oocyte and the nurse cell compartment. Ultimately, the leading edges of the centripetal cells meet the border cells and in this way the entire anterior oocyte pole becomes covered with FCs. Just prior to complete separation of nurse cells from the oocyte, the nurse cell cytoplasm rapidly flows into the oocyte. This process, known as nurse cell dumping or terminal injection, is linked with undergoing apoptosis of all nurse cells (MCCALL \& STELLER 1998; MATOVA et al. 1999). At about this time, a second signaling by Gurken proteins forces the mainbody FCs covering the anterior dorsal aspect of the oocyte to adopt a dorsal fate (for reviews see: DOBENS \& RAFTERY 2000; DORMAN et al. 2004; BERG 2005). As a consequence of this signaling, two dorso-lateral groups of FCs migrate anteriorly and form two elongated epithelial appendages (TRAN \& BERG 2003; DORMAN et al. 2004; BERG 2005). During the final stages of oogenesis all eight FC subpopulations cooperate in the formation of a regionally differentiated eggshell (MARGARITIS et al. 1980; MARGARITIS 1985; DOBENS \& RAFTERY 2000; HORNE-BADOVINAC \& BILDER 2005; WU et al. 2008).

Diptera comprise an estimated 124000 species which are traditionally separated into lower (Nematocera) and higher (Brachycera) flies (YEATES $\&$ WIEGMANN 1999). The latter group is further split into two clades: Orthorrhapha and Cyclorrhapha, which constitutes the most derived dipteran lineage, containing among others Muscomorpha and Drosophila (YEATES 2002; WIEGMANN et al. 2003).

Although the process of oogenesis in other dipteran groups has not been as well characterized as in Drosophila, the existing morphological data indicates that in dipterans, the functioning of the ovarian follicles is group-specific and may significantly differ from that of the model fruit fly. Comparative studies of the ovaries in other brachycerous flies have established that these differences concern primarily the mode of FC diversification and oocyte/nurse cells interactions (DE LOOF et al. 1990; JABŁOŃSKA \& BILIŃSKI 1998; KUBRAKIEWICZ et al. 2003; TWORZYDŁO et al. 2005). These studies also revealed that extensive and coordinated FC movements are characteristic only for Drosophila and other representatives of the Cyclorrhapha. In contrast, in ovarian follicles of Orthorrhapha, FC migration is noticeably reduced 
and hence the number of FC subpopulations is significantly lower. Decreased FC motility coincides with the appearance of long oocyte protrusions that penetrate anteriorly between the nurse cells and FCs, leading to partial embracement of the nurse cell compartment by a layer of the ooplasm (TWORZYDŁO et al. 2005). In this way, a progressively higher number of FCs contacts the oocyte and acquire the mainbody characteristics (TWORZYDŁO et al. 2005).

Here, we present the results of ultrastructural analysis of FC morphogenesis in another orthorrhaphous fly, the horse fly Haematopota italica. We have found that in the previtellogenic follicles of this species, the diversification process generates six FC subpopulations, only one of which is migratory.

\section{Material and Methods}

Adult specimens of Haematopota italica were collected in southeastern Poland near Kraków. Ovaries were dissected and fixed in $2.5 \%$ glutaraldehyde in $0.1 \mathrm{M}$ phosphate buffer ( $\mathrm{pH} 7.4$ ), rinsed and postfixed in $2 \%$ osmium tetroxide in the same buffer. After dehydration in a series of ethanol and acetone solutions, the material was embedded in Epon 812 (Fullam, Latham, NY). Semithin sections $(0.6 \mu \mathrm{m}$ thick $)$ were stained with methylene blue and examined with a Leica DMR microscope. Ultrathin sections ( $80 \mathrm{~nm}$ thick) were contrasted with uranyl acetate and lead citrate according to standard protocols and analysed with a JEM 100 SX or Zeiss EM 900 electron microscopes, at 80 $\mathrm{kV}$. FC diversification was examined in 2-4 ovarian follicles at the same stage of development.

\section{Results}

The ovaries of Haematopota italica consist of several dozen polytrophic ovarioles attached to elongated lateral oviducts. The anterior part of each ovariole is composed of a terminal filament that is followed by a short germarium containing clusters of differentiating germ cells (not shown). The remaining part of the ovariole, the vitellarium, comprises two or three linearly arranged ovarian follicles (or egg chambers). Each follicle consists of 16 germ cells (an oocyte +15 accompanying nurse cells) that are surrounded by a monolayer of mesodermal FCs forming the follicular epithelium (Figs 1-3). Neighboring ovarian follicles are connected by short interfollicular stalks composed of 3-6 flattened somatic cells (Figs 2, 3). For a detailed description of ovaries in orthorrhaphous flies, see KUBRAKIEWICZ et al. (2003) and TWORZYDŁO et al. (2005).

The process of oogenesis in representatives of orthorrhaphous flies has been arbitrarily subdivided into six consecutive stages: early, mid, and advanced previtellogenesis, early and advanced vitellogenesis, and choriogenesis (KUBRAKIEWICZ et al. 2003). In this study, we present the results of an ultrastructural analysis of early to late previtellogenic ovarian follicles, focusing on the morphology of the FCs at the ovarian follicle poles.

\section{Early previtellogenesis}

The early previtellogenic ovarian follicles lie in direct contact with the germarium. Each follicle consists of a small, lense-shaped oocyte and a relatively large nurse cell compartment (Fig. 6a). The oocyte nucleus (germinal vesicle) resides in the central region of the ooplasm, and contains condensed chromatin (the karyosome) immersed in translucent karyoplasm. The nurse cell nuclei are surrounded by a deeply folded nuclear envelope, and comprise several nucleoli and chromatin aggregates (not shown).

Even in the youngest previtellogenic follicles, the FCs are already diversified into five morphologically recognizable subpopulations (schematically represented in Fig. 6a):

1. Anterior PCs (aPCs) situated at the anterior pole of the follicle, i.e. at the anterior pole of the nurse cell compartment,

2. FCs surrounding the anterior PCs, termed border cells (BCs),

3. Cuboidal FCs (cFCs) covering the lateral aspects of the follicle,

4. FCs surrounding the posterior PCs, termed border-like cells (BLCs),

5. Posterior PCs (pPCs) situated at the posterior pole of the follicle, i.e. at the posterior pole of the oocyte, contacting the first interfollicular stalk.

FCs located at the extremities of the ovarian follicle (i.e. aPCs $+\mathrm{BCs}$ at the anterior pole, and pPCs + BLCs at the posterior one) form characteristic clusters that will be referred to as anterior $\mathrm{P} / \mathrm{BC}$ and posterior P/BL clusters, respectively (Fig. 6a). Morphologically, the posterior $\mathrm{P} / \mathrm{BL}$ clusters are more distinct and can be easily recognized even in semithin sections (Fig. 7 inset). Analysis of serial ultrathin sections showed that these clusters consist of 3 or 4 centrally located pPCs and 7-8 circumferentially placed BLCs (Fig. 7). Ultrastructural analysis indicated additionally that the pPCs are firmly and tightly surrounded by broad extensions of the BLCs (Fig. 7). The pPCs have large, 

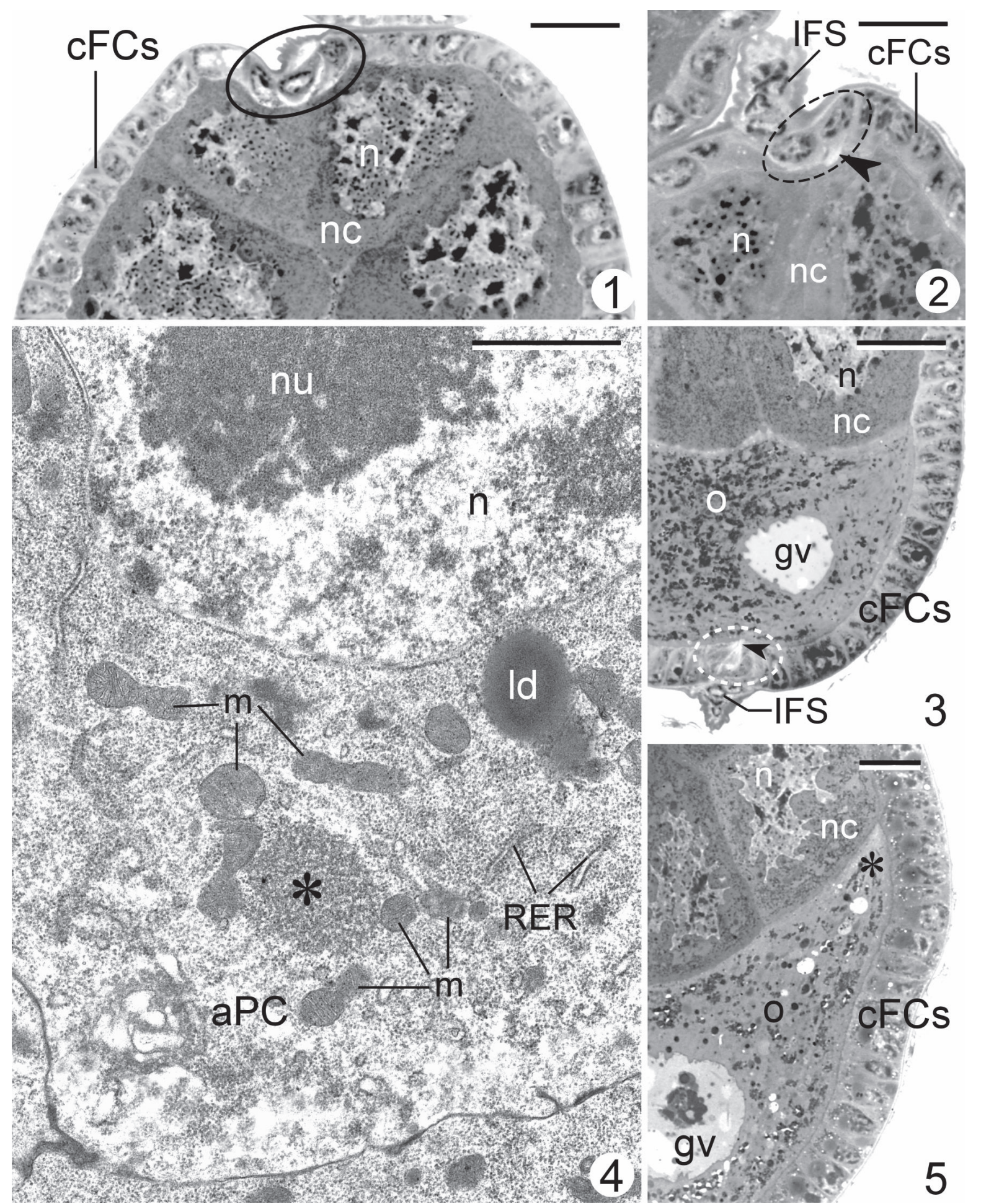

Figs 1-5. Fig. 1. The anterior part of the nurse cell compartment in the mid-previtellogenic ovarian follicle. Note a morphologically distinct $\mathrm{P} / \mathrm{BC}$ cluster (encircled) at the anterior pole and cuboidal follicular cells (cFCs) covering the lateral aspects of the nurse cell (nc) compartment. $\mathrm{n}$ - nurse cell nucleus. Semithin longitudinal section, methylene blue. Bar $=30 \mu \mathrm{m}$. Fig. 2. Fragments of two neighboring previtellogenic ovarian follicles separated by an interfollicular stock (IFS). The anterior polar cells (encircled) reside just beneath the IFS and over the nurse cells (nc). Note a large cytoplasmic projection (arrowhead) that extends from a polar cell apex into the nurse cell cytoplasm. $\mathrm{cFCs}$ - cuboidal follicular cells, $\mathrm{n}$ - nucleus. Semithin longitudinal section, methylene blue. Bar $=20 \mu \mathrm{m}$. Fig. 3. The posterior pole of the mid-previtellogenic ovarian follicle. The lateral aspects of the oocyte (o) are covered by cuboidal follicular cells (cFCs) except for the posterior pole, which is occupied by the P/BL cluster (encircled with a dashed line). Note cytoplasmic projections (arrowhead) of the P/BL cell apexes wedged into the oocyte cytoplasm. gv - germinal vesicle, IFS - interfollicular stock, $\mathrm{n}$ - nurse cell nucleus, $\mathrm{nc}$ - nurse cell. Semithin longitudinal section, methylene blue. Bar $=30 \mu \mathrm{m}$. Fig. 4. Ultrastructure of the anterior polar cell (aPC) in the previtellogenic follicle. The aPC cytoplasm contains a large accumulation of nuage-like material (aster) in contact with mitochondria (m). ld - lipid droplet, $\mathrm{n}$ - nucleus, nu - nucleolus, RER - rough endoplasmic reticulum. TEM micrograph. Bar = $1 \mu \mathrm{m}$. Fig. 5. In the late previtellogenic follicle, the periphery of the oocyte (o) forms broad protrusions (asterisk) penetrating between the nurse cells (nc) and the cuboidal follicular cells (cFCs). gv - germinal vesicle, $\mathrm{n}$ - nucleus. Semithin longitudinal section, methylene blue. $\mathrm{Bar}=20 \mu \mathrm{m}$. 


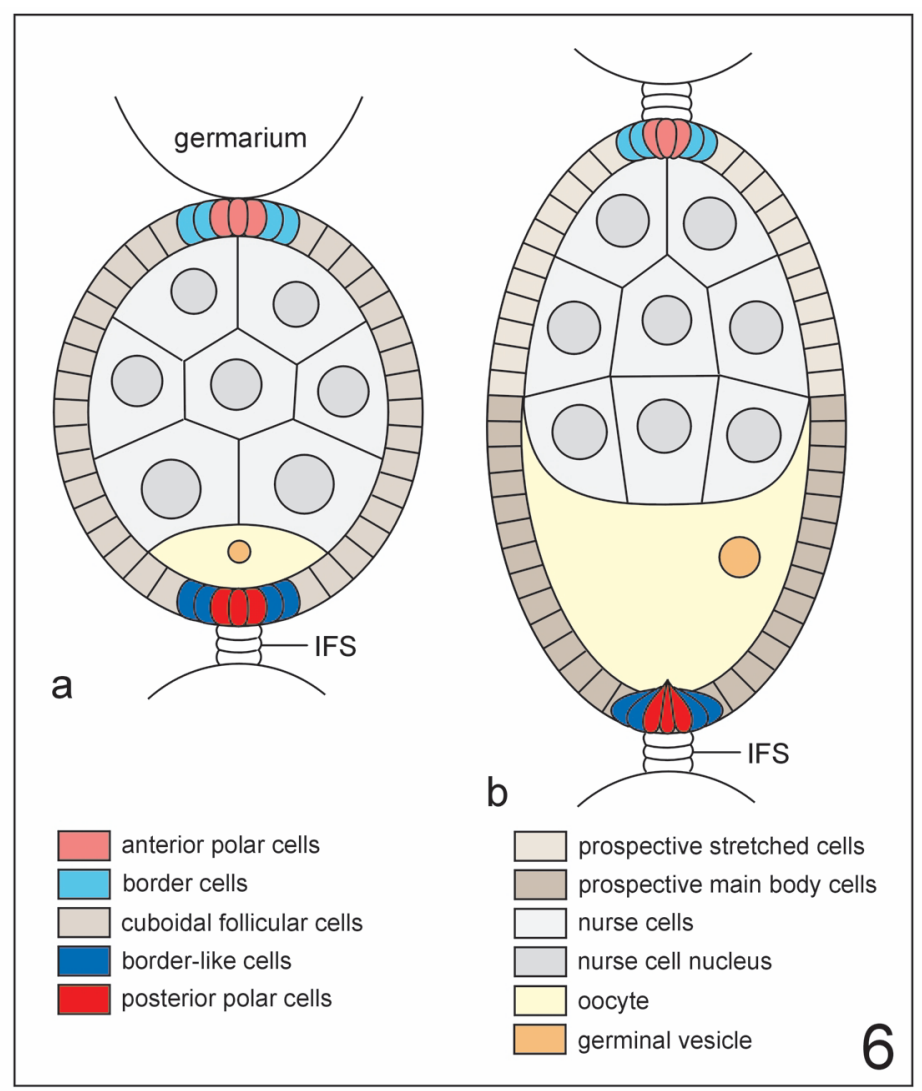

Fig. 6. A schematic representation of the early (a) and late (b) previtellogenic ovarian follicles of $H$. italica showing morphologically distinct follicular cell subpopulations (color-coded) resulting from the diversification process. IFS interfollicular stock.

roughly spherical nuclei (Fig. 7); their cytoplasm comprises numerous mitochondria, individual cisternae of the rough endoplasmic reticulum (RER), and conspicuous aggregates of nuage material (Fig. 7, asterisk). These aggregates often remain in direct contact with mitochondria (Fig. 7). The BLCs are equipped with elongated, often beanshaped nuclei and contain free ribosomes, RER elements, Golgi complexes, and mitochondria (Fig. 7). Within the cytoplasm of the BLC extensions, a parallel arrangement of microtubules is evident (not shown).

At this stage of oogenesis, the anterior $\mathrm{P} / \mathrm{BC}$ clusters are morphologically less distinct and consist of 2 or 3 "inner" PCs and up to 7 "outer" BCs. Structurally, the anterior PCs are similar to the posterior ones: their cytoplasm contains mitochondria, cisternae of RER and most significantly, large nuage aggregates (Fig. 4).

\section{Mid and late previtellogenesis}

The volume of the oocyte gradually increases during mid and late previtellogenesis. Simultaneously, the periphery of the oocyte sends out broad protrusions that penetrate between the nurse cell compartment and the surrounding $\mathrm{cFCs}$ (compare Figs 3 and 5). As oogenesis progresses, these protrusions expand anteriorly and fuse laterally, leading to the partial envelopment of the nurse cell compartment by a layer of ooplasm (for a detailed description of the successive stages of oogenesis in orthorrhaphous flies see TWORZYDEO et al. 2005). The germinal vesicle starts to shift towards the oocyte periphery (Figs 3, 5) before the onset of yolk incorporation (vitellogenesis).

Throughout mid previtellogenesis, FCs remain diversified into the 5 above-mentioned subpopulations: aPCs $+\mathrm{BCs}$ forming the anterior $\mathrm{P} / \mathrm{BC}$ cluster, cFCs, BLCs and pPCs forming the posterior P/BL cluster; Figs 1-3, 8 (upper inset). At the onset of mid-previtellogenesis, cells of the posterior $\mathrm{P} / \mathrm{BL}$ cluster rearrange and form a compact discshaped assemblage (Fig. 3). At apexes of all cells forming this assemblage (i.e. the pPCs and BLCs) conspicuous projections filled with microtubules arranged in parallel and rows of tiny smoothsurfaced vesicles develop (Fig. 3, arrowhead; Fig. 8 lower inset). The projections adhere to each other and form a single, presumably rigid bunch that comes into contact with the oocyte plasma membrane and penetrates between the oocyte microvilli and into the ooplasm (Fig. 8). Adherens 


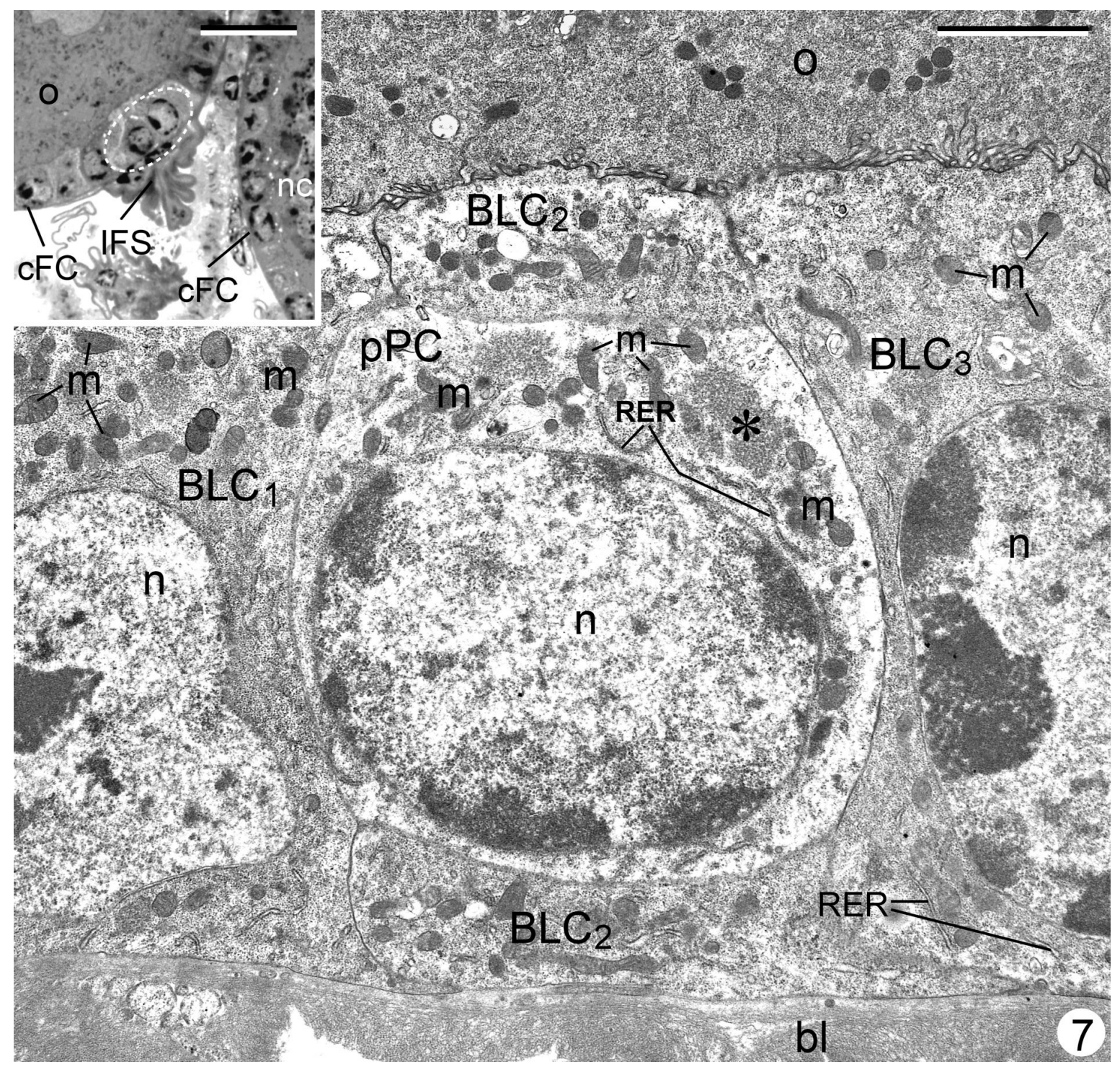

Fig. 7. The arrangement of the follicular cells within the posterior $\mathrm{P} / \mathrm{BL}$ cluster in the early previtellogenic follicle. The centrally located posterior polar cell $(\mathrm{pPC})$ is surrounded by border-like follicle cells $\left(\mathrm{BLC}_{1}, \mathrm{BLC}_{2}, \mathrm{BLC}_{3}\right)$. Note nuage aggregate (asterisk) in contact with mitochondria (m). bl - basal lamina, $\mathrm{n}$ - nucleus, o - oocyte, RER - cisternae of the rough endoplasmic reticulum. TEM micrograph. Bar $=2 \mu \mathrm{m}$.

Inset: fragments of two neighboring early previtellogenic follicles. The posterior P/BL cluster is encircled with a dashed line. cFC - cuboidal follicle cells, IFS - interfollicular stock, nc - nurse cell, o- oocyte. Semithin section, methylene blue. Bar $=20 \mu \mathrm{m}$.

junctions occur between individual pPC and BLC projections as well as between these projections and the opposite cFCs (Fig. 8 lower inset, large arrowheads). In addition, pPC membranes are equipped with finger-like processes entering deep into the cytoplasm of the neighboring BLCs (Fig. 8 , empty arrows). It can be suggested that these processes together with adherens junctions ensure the stability of the cluster.

At mid-previtellogenesis, the cuboidal FCs separating the anterior $\mathrm{P} / \mathrm{B}$ and posterior $\mathrm{P} / \mathrm{BL}$ clusters from each other, markedly enlarge. In the apical parts of these cells, prominent complexes of concentrically arranged RER cisternae arise (Fig. 9). EM analysis showed that each RER complex contains a large, centrally located lipid droplet (Fig. 9).
The posterior $\mathrm{P} / \mathrm{BL}$ cluster is tightly surrounded by characteristically bent, most posterior cFCs (Fig. 9). Between apical plasma membranes of these cells, prominent adherens junctions are present (Fig. 9).

The basal lamina covering basal surfaces of the pPCs as well as BLCs is corrugated and equipped with variously shaped processes (Fig. 9 inset). Careful analysis of electron micrographs revealed that along the plasma membrane adhering to these processes small accumulations of dense material are present (Fig. 9 inset). Since these accumulations are structurally similar to the cytoplasmic plaques of hemidesmosomes, we suggest that they may ensure the fixed position of the posterior $\mathrm{P} / \mathrm{BL}$ cluster in relation to the posterior pole of the oocyte. 


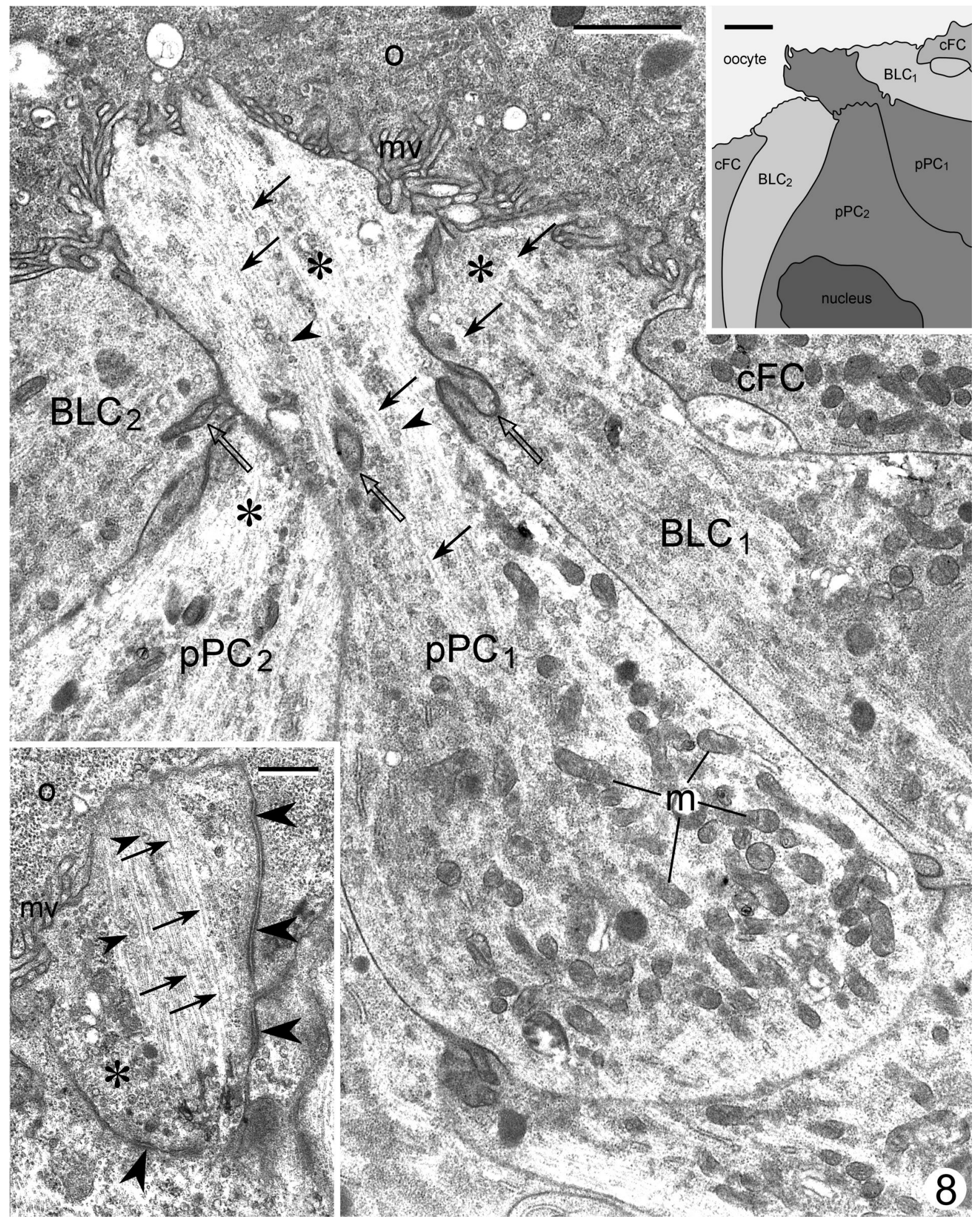

Fig. 8. The ultrastructure of the posterior P/BL cluster in the late previtellogenic ovarian follicle. A schematic drawing based on a single ultrathin section (upper inset) shows a complex arrangement of the follicular cells within the cluster. The TEM micrograph shows a different section obtained from the same cluster. The apical parts of both the posterior polar cells ( $\mathrm{pPC}_{1}$, $\mathrm{pPC}_{2}$ ) and border-like cells $\left(\mathrm{BLC}_{1}, \mathrm{BLC}_{2}\right)$ are extended into large cytoplasmic projections (asterisks) that form a bundle penetrating between the microvilli (mv) of the oocyte (o) and into the ooplasm. The cytoplasmic projections of the posterior PCs and BLCs are bound together by adherens junctions (lower inset, large arrowheads) and filled with parallel arranged microtubules (arrows) and tiny smooth-surfaced vesicles (small arrowheads). Note finger-like processes of the pPC cell membranes (empty arrows) entering deep into the cytoplasm of the neighboring BLCs. cFC - cuboidal follicular cell, $\mathrm{m}-$ mitochondria. Bars $=1 \mu \mathrm{m}$; upper inset, $2 \mu \mathrm{m}$; lower inset, $500 \mathrm{~nm}$. 


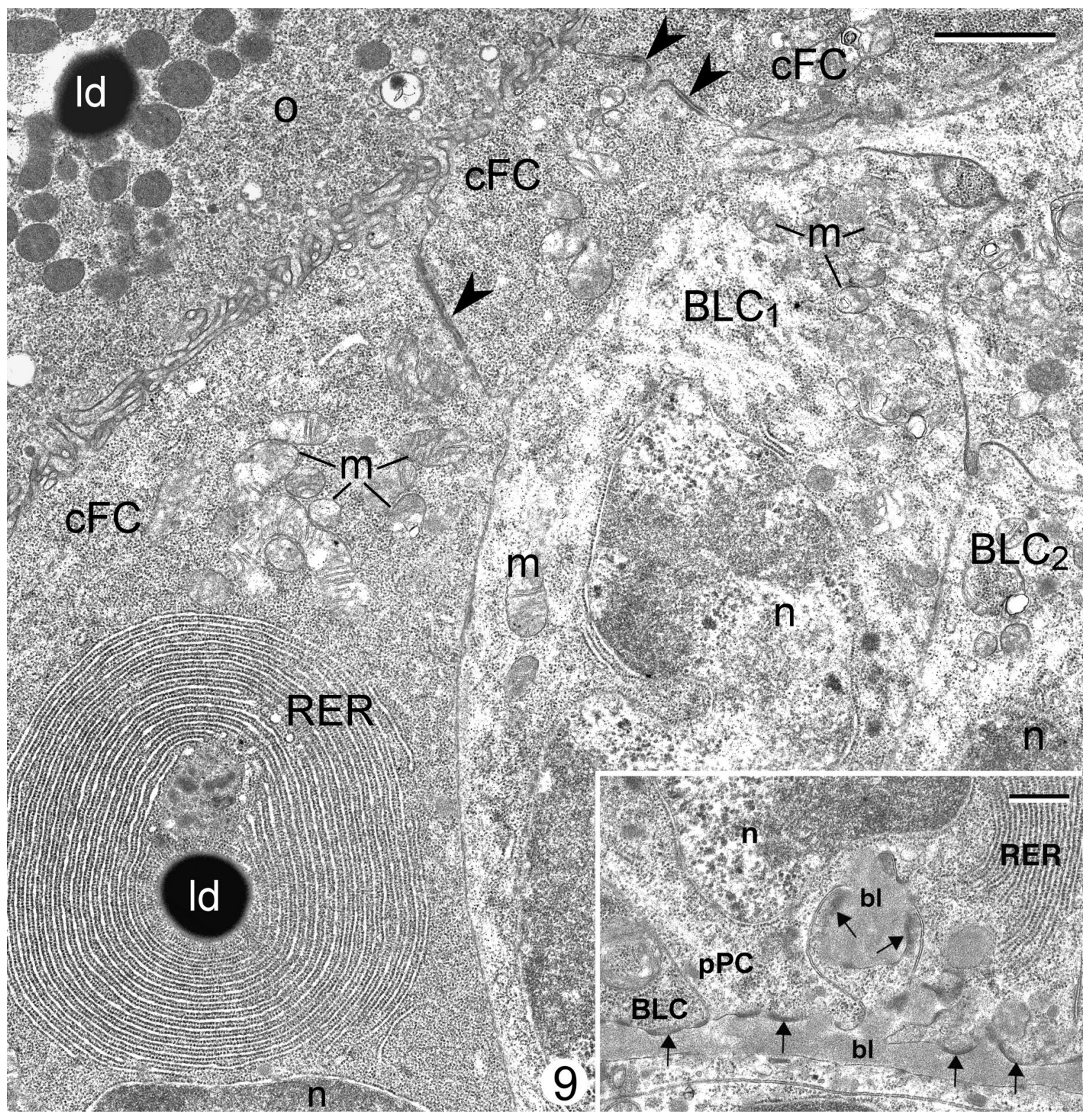

Fig. 9. The cuboidal follicular cells $(\mathrm{cFC})$ and adjacent border-like cells $\left(\mathrm{BLC}_{1}, \mathrm{BLC}_{2}\right)$ differ noticeably in their ultrastructure. The apical cytoplasm of the $\mathrm{cFC}$ contains characteristic concentric complexes of rough endoplasmic reticulum cisternae (RER) with a centrally located lipid droplet (ld). The neighboring cFCs are connected by prominent adherens junctions (arrowheads). $\mathrm{m}-$ mitochondria, $\mathrm{n}$ - nucleus, o- oocyte. TEM micrograph. $\mathrm{Bar}=1 \mu \mathrm{m}$.

Inset: Hemidesmosomes (arrows) attach the basal plasma membranes of the posterior polar cell (pPC) and border-like cell (BLC) to the corrugated basal lamina (bl). $\mathrm{n}$ - nucleus, RER - rough endoplasmic reticulum. TEM micrograph. $\mathrm{Bar}=500 \mathrm{~nm}$.

Although cells of the anterior $\mathrm{P} / \mathrm{BC}$ cluster are in general less evident than those of the posterior cluster, they can be relatively easily recognized in both semithin and ultrathin sections (Figs 1-2, 10). The center of the anterior cluster is occupied by roughly spherical aPCs (Fig. 10). They contain characteristic lobed nuclei, mitochondria, RER cisternae, Golgi complexes, nuage aggregates and numerous microtubules (Fig. 10). The aPCs are surrounded by bent, often crescent-shaped BCs (Fig. 10 inset). Cells of the anterior $\mathrm{P} / \mathrm{BC}$ cluster are equipped with broad projections contacting the membranes of the nurse cells (Figs 10, asterisk; 11). The projections comprise irregularly distributed microtubules, ribosomes and individual smooth-surfaced vesicles (Fig. 11). The plasma membrane of the projections is covered with small microvilli-like processes that penetrate between plasma membranes of the neighboring nurse cells (Figs 10, 11).

In the most advanced previtellogenic follicles we have studied, the initially morphologically 




Figs 10-11. Fig. 10. The ultrastructure of the anterior $\mathrm{P} / \mathrm{BC}$ cluster in the late previtellogenic ovarian follicle. The anterior polar cell (aPC1) is flanked by crescent-shaped BC (inset) and is equipped with a broad cytoplasmic projection (empty star) extending from the apex of the aPC1 and penetrating between the nurse cells $\left(\mathrm{nc}_{1}, \mathrm{nc}_{2}\right)$. The plasma membrane of the projection is covered with microvilli-like processes (mv). Within the PC cytoplasm, in the vicinity of a lobed nucleus (n1, n2), a nuage aggregate (asterisk) in contact with mitochondria $(\mathrm{m})$ is visible. arrowhead - a connection between two lobes $(\mathrm{n} 1, \mathrm{n} 2)$ of the nucleus, arrows - microtubules, Gc - Golgi complex, $\mathrm{n}$ - nucleus, $\mathrm{ncm}$ - cell membrane between the nurse cells, nu nucleolus. RER - rough endoplasmic reticulum. TEM micrographs. Bars $=1 \mu \mathrm{m}$. Fig. 11. The apex of the cytoplasmic projection of the anterior polar cell (aPC) penetrating between nurse cells $\left(\mathrm{nc}_{1}, \mathrm{nc}_{2}\right)$. The projection contains microtubules (encircled) and small smooth-surfaced vesicles (arrowheads). $\mathrm{m}$ - mitochondria, $\mathrm{mv}$ - microvilli-like processes, $\mathrm{ncm}$ - cell membrane between the nurse cells. TEM micrograph. $\mathrm{Bar}=500 \mathrm{~nm}$. 
similar cuboidal FCs undergo further diversification into two subpopulations: flat cells, resembling Drosophila stretched FCs (1), covering the nurse cells, and larger columnar mainbody FCs (2) that remain in contact with the lateral aspects of the oocyte (schematically represented in Fig. 6b; see also JAGLARZ et al. 2008 for further details). This process increases to six the final number of FC subpopulations in $\mathrm{H}$. italica ovarian follicles.

\section{Discussion}

Our studies have shown that during previtellogenic stages of oogenesis in the horse fly, $H$. italica, FCs diversify into six subpopulations (aPCs, BCs, SCs, mainbody, BLCs, and pPCs), and that cells located at the extremities of the follicle (i.e. aPCs $+\mathrm{BCs}$ at the anterior pole of the nurse cell compartment, and pPCs + BLCs at the posterior oocyte pole) form well defined clusters. Since these clusters are morphologically similar during early previtellogenesis, we suggest that the "polar" domains of the follicular epithelium in the horse fly, as those of the fruit fly Drosophila melanogaster, are initially symmetrical. In Drosophila, this early symmetry is broken by the Gurken signal released from the oocyte posterior pole (for details see the Introduction). In consequence, during successive stages of oogenesis the anterior and posterior domains of the fruit fly follicular epithelium adopt different fates, and participate in the formation of morphologically and functionally distinct regional specializations of the eggshell (MARGARITIS et al. 1980; MARGARITIS 1985; DOBENS \& RAFTERY 2000; HORNE-BADOVINAC \& BILDER 2005). In the studied horse fly, the anterior versus posterior clusters become morphologically distinct from the onset of mid previtellogenesis, suggesting that in this species, as in the fruit fly, the symmetry of the polar domains of the follicular epithelium is lost relatively early. In contrast to the situation found in Drosophila and Haematopota, in some other brachycerous flies (e.g. rhagionids) the symmetry of the polar domains of the FCs is retained much longer as evidenced by the morphological similarity of BCs (at the anterior pole) and BLCs (at the posterior one) till mid vitellogenesis (TWORZYDŁO et al. 2005). In this context it is interesting to note that eggshells of certain neuropterans (KUBRAKIEWICZ et al. 2005) and dipterans (HINTON 1981), as well as those laid by Drosophila gurken mutants (GONZALEZ-REYES et al. 1995), are equipped with two structurally identical surface specializations (micropyles?) located at opposite poles of the oocyte. These findings clearly indicate that in some insects the polar domains of the follicular epithelium must be symmetrical up to the final stages of oogenesis and it is tempting to speculate that this symmetry might result from the absence of Gurken signaling.

Our EM studies have also shown that during mid to advanced previtellogenesis, cells of the anterior $(\mathrm{PCs}+\mathrm{BCs})$ and posterior (PCs $+\mathrm{BLCs})$ clusters form conspicuous projections. Interestingly, the projections of the anterior versus posterior cells differ morphologically and appear to participate in different processes. The cytoplasmic projections of the anterior cluster are structurally similar to the projections formed by migrating border cells of other dipteran species (NIEWIADOMSKA et al. 1999; KUBRAKIEWICZ et al. 2003). They are broad, comprise irregularly arranged microtubules, and their apexes are equipped with small microvillilike extensions that penetrate between the plasma membranes of the adjacent nurse cells. These findings suggest that in subsequent stages of oogenesis, the "anterior" projections will support migration of the anterior cluster (PCs and BCs) towards the oocyte anterior pole. In contrast, the projections of the posterior PCs and BLCs are slender and contain numerous microtubules arranged in a parallel manner. All these projection merge forming a single bunch that penetrates between the oocyte microvilli and into the cortical ooplasm. Similar rigid, filled with an elaborate cytoskeleton, projections of FCs have previously been described in several insect species and implicated in the formation or molding of such eggshell specializations as micropyle/aeropyle openings or attachment structures (MARGARITIS 1984; WENZEL et al. 1990; ZARANI \& MARGARITIS 1991; ZAWADZKA et al. 1997; KUBRAKIEWICZ et al. 2005). Although the morphology of the horse fly eggshells has never been studied, it is known that the eggs of these insects develop attached to leaves, stems of plants, bark or stones (HINTON 1981). In view of this, we suggest that in Haematopota, the projections of the posterior $\mathrm{P} / \mathrm{BL}$ cluster are involved in the formation of the specialization of the chorion responsible for either respiration of the embryo or attachment of the eggs to the appropriate substrate.

In most animals, germ cells contain large perinuclear aggregates of electron-dense granular material vaguely termed "nuage". On the basis of ultrastructural and cytochemical studies, it is believed that nuage represents a direct precursor of germinal (termed also polar or P) granules, determinants of the germ cell fate (for a review see EDDY 1975; SAFFMAN \& LASKO 1999; KLOC et al. 2004). A complete list of molecular components of nuage and germinal granules is not yet available, but it has been shown that they contain both proteins (e.g. Vasa like DEAD box RNA helicases; Aubergine, a protein implicated in RNA regulation via microRNAs) and mRNAs (e.g. Xcat2) 
(KLOC et al. 2002; BILIŃSKI et al. 2004; LINDER \& LASKO 2006; SEYDOUX \& BROWN 2006; EULALIO et al. 2007). Recent analyses have revealed that nuage shares its components with small cytoplasmic foci present in somatic cells, termed processing $(\mathrm{P})$ bodies (for a discussion of the function and composition of P bodies see SEYDOUX \& BROWN 2006; EUlalio et al. 2007). In the light of these findings, it has been hypothesized that the germinal granules (and their precursor, nuage) are germline equivalents of somatic P bodies. Unexpectedly, our EM analysis has shown that some somatic (follicular) cells of Haematopota, i.e. the anterior as well posterior PCs, contain large aggregates of nuage-like material. To our knowlegde, the occurrence of nuage in the follicular cells has not been reported to date. Since molecular composition of nuage aggregates has not been analysed in Haematopota $\mathrm{PCs}$, this rather surprising finding cannot be adequately interpreted. It might only be postulated that they represent exceptionally large $\mathrm{P}$ bodies and that their occurrence in (somatic) PCs may be related to the specific "organizer" activity of these cells (GRAMMONT \& IRVINE 2002).

The molecular mechanisms underlying the morphogenesis and diversification of the follicular epithelium are best characterized in the model insect, Drosophila melanogaster. In developing ovarian follicles of Drosophila, the initially uniform follicular epithelium is patterned into several functionally different FC subpopulations (reviewed in DOBENS \& RAFTERY 2000; HORNE-BADOVINAC \& BILDER 2005; WU et al. 2008). At least some of these (i.e. the mainbody FCs, BCs and CCs) are capable of migrating over the germ cells. Both the specification of these subpopulations and their movements depend on inductive signaling mediated by various ligands, their corresponding receptors, and extensive rearrangements of the cytoskeleton (reviewed in DOBENS \& RAFTERY 2000; HORNE-BADOVINAC \& BILDER 2005; Wu et al. 2008). As oogenesis progresses, the FC subpopulations reach their final destination within the ovarian follicle and form the regionally complex eggshell. Previous comparative morphological studies have shown that the FC patterning described in detail in the fruit fly is characteristic only for the closest relatives of this model species, that is representatives of higher brachycerans or the Cyclorrhapha (DE LOOF et al. 1990; JABŁOŃSKA \& BILIŃSKI 1998; KUBRAKIEWICZ et al. 1998 2003; MAZURKIEWICZ \& KUBRAKIEWICZ 2005; TWORZYDEO et al. 2005). In more distant relatives of Drosophila, i.e. lower brachycerans, the Orthorrhapha, both the number of FC subpopulations and the number of actively migrating subpopulations are significantly lower (KUBRAKIEWICZ et al. 1998, 2003; TWORZYDEO et al. 2005). Our present results support this idea showing that in the studied representative of the family Tabanidae, the number of FC subpopulations is relatively low and equals 6. Moreover, in Haematopota the only migrating $\mathrm{FCs}$ are $\mathrm{BCs}$, and the remaining $\mathrm{FC}$ subpopulation, in contrast to Drosophila, do not show any migratory activity.

\section{Acknowledgements}

We would like to thank Prof. J. KUBRAKIEWICZ (University of Wrocław) for providing EM facilities. We are grateful to Ms. W. JANKOWSKA for excellent technical assistance.

\section{References}

BERG C. A. 2005. The Drosophila shell game: patterning genes and morphological change. Trends Genetics 21: 346-354.

Besse F., PRET A-M. 2003. Apoptosis-mediated cell death within the ovarian polar cell lineage of Drosophila melanogaster. Development 130: 1017-1027.

BILIŃSKI S. M. 1998. Ovaries, oogenesis and insect phylogeny. Introductory remarks. Folia Histochem. Cytobiol. 36: $43-145$.

BilińSKi S. M., JAGLARZ M. K., SZYMAŃSKA B., ETKIN L. D., KLOC M. 2004. Sm proteins, the constituents of the spliceosome, are components of nuage and mitochondrial cement in Xenopus oocytes. Exp. Cell. Res. 299: 171-178.

BÜNING J. 1994. The insect ovary. Ultrastructure, previtellogenic growth and evolution. Chapman and Hall, London.

DE LoOf A., GeYsen J., CARDOEN J., VERACHTER B. 1990. Comparative developmental physiology and molecular cytology of the polytrophic ovarian follicles of the blowfly Sarcophaga bullata and fruit fly Drosophila melanogaster. Comp. Biochem. Physiol. 96: 309-321.

DENEF N., SCHÜPBACH T. 2003. Patterning: JAK-STAT signalling in the Drosophila follicular epithelium. Curr. Biol. 13: R388-R390.

DOBENS L. L., RAFTERY L. A. 2000. Integration of epithelial patterning and morphogenesis in Drosophila ovarian follicle cells. Dev. Dynam. 218: 80-93.

DORMan J. B., JAMES K. E., Fraser S. E., KiEhart D. P., BERG C. A. 2004. bullwinkle is required for epithelial morphogenesis during Drosophila oogenesis. Dev. Biol. 267: 320-341.

EDDY E. M. 1975. Germ plasm and the differentiation of the germ cell line. Int. Rev. Cytol. 43: 229-280.

Eulalio A., BEHM-Ansmant I., IZAURRALDE E. 2007. P bodies: at the crossroads of post-transcriptional pathways. Nat. Rev. Mol. Cell. Biol. 8: 9-22.

GonzaleZ-Reyes A., HeAther E., St Johnston D. 1995. Polarization of both major body axes in Drosophila by gurken-torpedo signalling. Nature 375: 654-658.

GonZALEZ-REYES A., ST JOHNSTON D. 1998. Patterning of the follicle cell epithelium along the anterior-posterior axis during Drosophila oogenesis. Development 125: 2837-2846.

GRAMMONT M., IRVINE K. D. 2001. fringe and Notch specify polar cell fate during Drosophila oogenesis. Development 128: $2243-2253$

GRAMMONT M., IRVINE K. D. 2002. Organizer activity of the polar cells during Drosophila oogenesis. Development 129: 5131-5140.

Hinton H. E. 1981. Biology of Insect Eggs. Pergamon Press, Oxford. 
HoRne-BADOVInAC S., BILDER D. 2005. Mass transit: epithelial morphogenesis in the Drosophila egg chamber. Dev. Dyn. 232: 559-574.

JABŁOŃSKA A., BILIŃSKI S. M. 1998. Structure of ovaries and oogenesis in Tachypeza nubila (Diptera, Empidoidea: Hybotidae). Folia Morph. 57: 26.

JaglarZ M. K., KRZEMiŃSKi W., Biliński S. M. 2008 Structure of the ovaries and follicular epithelium morphogenesis in Drosophila and its kin. Dev. Genes Evol. 218 : 399-411.

Kloc M., BiLIŃSKi～S. M., ETKIN L. D. 2004. The Balbiani body and germ cell determinants: 150 years later. Curr. Top. Dev. Biol. 59: 1-36.

KLOC M., ZEARFoss R. N., ETKIN L. D. 2002. Mechanisms of subcellular mRNA localization. Cell 108: 533-544.

Kubrakiewicz J., Biliński S. M., MaZURKIEWiCZ M. 1998. Diptera - ovary structure and oogenesis in midges and flies. Folia Histochem. Cytobiol. 36: 197-203.

KUBRAKIEWICZ J., JABloŃSKA A., MAZURKIEWICZ M. BILIŃSKI S. M. 2003. Differentiation and diversification of the follicular cells in flies: insight from the studies of the lower brachycerans' ovaries. Genesis 36: 214-224.

KUBRAKIEWICZ J., JĘDRZEJOWSKA I., SZYMAŃSKA B., BILIŃSKI S. M. 2005. Micropyle in neuropterid insects. Structure and late stages of morphogenesis. Arthropod Struct. Dev. 34: 179-188.

LINDER P., LASKO P. 2006. Bent out of shape: RNA unwinding by the DEAD-box helicase Vasa. Cell 125: 219-221.

MARGARITIS L. H. 1984. Microtubules during formation of the micropylar canal in Drosophila melanogaster. Cell Biol. Int. Rep. 4: 317-321.

MARGARITIS L. H. 1985. Structure and physiology of the eggshell. (In: Comprehensive Insect Physiology, Biochemistry and Pharmacology, vol.1., Kerkut GA, Gilbert LI eds, Pergamon Press, Oxford): 153-226.

Margaritis L., Kafatos F., Petri W. 1980. The eggshell of Drosophila melanogaster: I. Fine structure of the layers and regions of the wild-type eggshell. J. Cell Sci. 43: 1-35.

Matova N., Mahajan-Miklos S., Mooseker M. S., COOLEY L. 1999. Drosophila Quail, a villin-related protein, bundles actin filaments in apoptotic nurse cells. Development 126: 5645-5657.

MAZURKIEWICZ M., KUBRAKIEWICZ J. 2005. Differentiation and diversification of follicular cells in polytrophic ovaries of crane flies (Diptera: Nematocera: Tipulomorpha and Trichoceridae). Tissue Cell 37: 367-377.

MCCALl K., STELLER H. 1998. Requirement for DCP-1 caspase during Drosophila oogenesis. Science 279: 230-234.

MONTELL D. J. 2003. Border-cell migration: the race is on. Nature Rev. Mol. Cell Biol. 4: 13-24.

Montell D. J. 2006. The social lives of migrating cells in Drosophila. Curr. Opin. Genet. Dev. 16: 374-83.
MOUSSIAN B., ROTH S. 2005. Dorsoventral axis formation in the Drosophila embryo - shaping and transducing a morphogen gradient. Curr. Biol. 15: R887-R899.

Niewiadomska P., GodT D., TEPASs U. 1999. DE-Cadherin is required for intercellular motility during Drosophila oogenesis. J. Cell Biol. 144: 533-547.

RAY R. P., SCHÜPBACH T. 1996. Intercellular signaling and the polarization of body axes during Drosophila oogenesis. Genes Dev. 10: 1711-1723.

RoTH S. 2001. Coordinating germ line and soma. Curr. Biol. 11: 779-781.

SAFFMAn E. E, LASKO P. 1999. Germline development in vertebrates and invertebrates. Cell Mol. Life Sci. 55: 1141-1163.

SEydoux G., BROWn R. E. 2006. Pathway to totipotency: lessons from germ cells. Cell 127: 891-904.

TRAN D. H., BERG C. A. 2003. bullwinkle and shark regulate dorsal-appendage morphogenesis in Drosophila oogenesis. Development 130: 6273-6282.

TworZydeo W., JABŁoŃSKA A., Kisiel E., BiLiŃSKi S. M. 2005. Differing strategies of patterning of follicular cells in higher and lower brachycerans (Diptera: Brachycera). Genesis 43: 49-58.

WenZEL F., GutZeit H. O., Zissler D. 1990. Morphogenesis of the micropylar apparatus in ovarian follicles of the fungus gnat Bradysia tritici (syn. Sciara ocellaris). Roux's Arch. Dev. Biol. 199: 146-155.

Wiegmann B. M., Yeates D. K., Thorn J. L., Kishino H. 2003. Time flies, a new molecular time scale for brachyceran fly evolution without a clock. Syst. Biol. 52: 745-756.

Wu X., TANwAR P. S., RAFTery L. A. 2008. Drosophila follicle cells: morphogenesis in an eggshell. Semin. Cell Dev. Biol. 19: 271-282.

Xi R., MCGREgOR J. R., HARRISON D. A. 2003. A gradient of JAK pathway activity patterns the anterior-posterior axis of the follicular epithelium. Dev. Cell 4: 167-177.

YEATES D. K. 2002. Relationships of extant lower Brachycera (Diptera): a quantitative synthesis of morphological characters. Zool. Scripta 31: 105-121.

YEATES D. K., WiEgMANN B. M. 1999. Congruence and controversy: toward a higher-level phylogeny of the Diptera. Ann. Rev. Entomol. 44: 397-428.

ZARANI F. E., MARGARITIS L. H. 1991. The eggshell of Drosophila melanogaster. VII. Formation of the micropylar canal and the role of the paracrystalline structure. Roux's Arch. Dev. Biol. 200: 95-103.

ZAWADZKA M., JANKOWSKA W., BILIŃSKI S. M. 1997. Egg shells of mallophagans and anoplurans (Insecta: Phthiraptera): morphogenesis of specialized regions and the relation to F-actin cytoskeleton of follicular cells. Tissue Cell 29: 665-673. 